\title{
The Prevalence of Cognitive Impairment among Older Adults in Jamaica
}

\author{
N Waldron ${ }^{1}$, H Laws², K James², D Willie-Tyndale ${ }^{1}$, D Holder-Nevins ${ }^{2}$, K Mitchell-Fearon ${ }^{2}$, W Abel ${ }^{2}$, D Eldemire-Shearer ${ }^{1}$
}

\begin{abstract}
Objective: This study sought to document the prevalence of cognitive impairment among a nationally representative sample of community-dwelling older adults and determine associated factors.

Methods: A survey of 2943 older adults was undertaken in four parishes in Jamaica. A two-stage cluster sampling methodology was used, with the first and second cluster units being enumeration districts and households, respectively. Cognitive impairment was assessed using the Mini-Mental State Examination tool. Bivariate analyses were used to explore relationships between cognitive impairment and sociodemographic and health characteristics. Significant variables were entered into a logistic regression model and adjusted odds ratios for likelihood of cognitive impairment obtained.

Results: Less than one in three persons had some level of cognitive impairment. Older age and lower levels of education independently predicted cognitive impairment (OR 1.05, 95\% CI 1.04, 1.06; OR $3.00,95 \%$ CI 2.23, 4.01). Older adults who limited their activities because of fear of falling (OR 1.35, $95 \%$ CI 1.09, 1.67), self-reported diabetes mellitus (OR 1.32, 95\% CI 1.05, 1.67), screened positive for depression (OR 1.02, 95\% CI 1.02, 1.03) and reported dependence in one or more activities of daily living (OR 2.47, 95\% CI 1.62, 3.78) were more likely to have cognitive impairment.

Conclusion: The prevalence of cognitive impairment in community-dwelling older adults is significantly higher than previously found in Jamaica, a middle-income developing country, but similar to that of populations with comparable age, education and income profile. Further exploration of risk factors may point to interventions for reducing cognitive impairment and associated morbidity.
\end{abstract}

Keywords: Cognitive impairment, Jamaica, Mini-Mental Status Examination, older adults

WIMJ Open 2015; 2 (2): 71

\section{INTRODUCTION}

Globally, the age-standardized prevalence of dementia has been estimated to be between $5 \%$ and $7 \%$ among persons aged 60 years and over (1). The highest prevalences documented were in Latin America and the Caribbean, with agestandardized rates of $8.5 \%$ and $8.1 \%$, respectively $(1,2)$. With advances in life expectancy and rapid population ageing, the prevalence of dementia is expected to increase. Almost 36 million people globally have dementia with an expected doubling in the next 20 years and an increase to 135 million by the year $2050(3,4)$.

Diagnosing dementia is a multi-stage process which begins with screening followed by diagnostic tests for those with abnormal results. The screening process identifies cognitive impairment and the most widely used instrument is the Mini-Mental State Examination [MMSE] (5). This instrument was designed to screen for cognitive deficits in several

From: ${ }^{1}$ Mona Ageing and Wellness Centre, Faculty of Medical Sciences and ${ }^{2}$ Department of Community Health and Psychiatry, Faculty of Medical Sciences, The University of the West Indies, Kingston 7, Jamaica.

Correspondence: Professor D Eldemire-Shearer, Mona Ageing and Wellness Centre, Faculty of Medical Sciences, The University of the West Indies, Kingston 7, Jamaica. E-mail: denise.eldemireshearer@uwimona.edu.jm domains including orientation (time and place), memory (immediate and short-term), attention and calculation, language and constructional praxis [figure copy] (5-7). The MMSE has been used extensively across many populations of different sociocultural background with reported excellent validity (8-12).

Scores on MMSE are greatly influenced by age and education level (13-15). Cognitive impairment and dementia have been associated with rural dwellers (16), increased rates of hospitalization $(17,18)$, increased risk for falls $(19,20)$, increased prevalence of fear of falling $(21,22)$, diabetes mellitus $(23,24)$, depression $(17,25)$, and dependence in activities of daily living [ADL] (26). There are conflicting studies on the association of gender and hypertension with cognitive impairment (27-29). The last nationally representative study on cognitive impairment in Jamaica was completed over two decades ago and reported a prevalence of $14.1 \%(30)$.

Against a backdrop of rapid population ageing, this study seeks to document the current prevalence of cognitive impairment among a nationally representative sample of community-dwelling older adults and determine its associated factors. 


\section{SUBJECTS AND METHODS}

A cross-sectional survey of 2943 older adults was done in 2012 in four parishes in Jamaica. These parishes collectively reflect the age, gender and urban/rural diversity of the Jamaican population. A two-stage cluster sampling methodology was used, with the first and second stage cluster units being enumeration districts and households, respectively. The methods used in this survey have been described previously (31).

The interviewer-administered survey instrument contained 196 questions on community and social relationships, socio-economic factors, lifestyle behaviours, health status and access/utilization behaviours. The instrument also included the following standard tools:

- the MMSE, an 11-item instrument designed to screen for cognitive impairment $(5,6)$. Two options of the MMSE "Place Orientation" item were modified for relevance to the typical home setting in Jamaica. Possible scores range from $0-30$ points, with higher scores indicative of better cognitive functioning. The cut-point of 21/22 (ie with scores of 21 and below indicative of cognitive impairment) was applied because of the age group surveyed and low educational attainment of older adults in Jamaica $(11,32)$. The scores were further categorized as $22-30$ points reflecting no cognitive impairment, while $18-21$ and $0-17$ points reflected mild cognitive impairment and severe cognitive impairment, respectively.

- the 20-item Zung Self-Rating Depression Scale (SDS), to assess depression. Raw SDS scores were converted to a 100-point index (SDS index) in which $<50$ points indicated no depression (normal mood), 50-59 points: mild depression, 60-69 points: moderate depression and $\geq 70$ points: severe depression $(33,34)$.

- the Katz Index of Independence in Activities of Daily Living (ADL) consisting of six questions on physical functioning (bathing, dressing, toileting, transferring, feeding and continence). The possible score range of the ADL was 0-6 points, which was dichotomized to dependent in at least one ADL $($ label $=1)$ and independent in all ADL [label =0] $(34,35)$.

The data were analysed with the assistance of the Statistical Package for Social Sciences, version 17, for Microsoft Windows. Chi-squared test for association was used to determine significant differences between the dependent variable (cognitive impairment: severe, mild, none) and covariates. The MMSE scale was subsequently dichotomized to older adults with no cognitive impairment (label = 0 ) and older adults with mild or severe cognitive impairment $($ label $=1)$. Using this as the outcome variable, a logistic regression model was developed to determine adjusted odds ratios (OR) and 95\% confidence intervals (CI) for significant covariates.

This study protocol was approved by the University Hospital of the West Indies/University of the West Indies/ Faculty of Medical Sciences Ethics Committee. Study participants or their legal guardians/caregivers provided informed consent.

\section{RESULTS}

\section{Sociodemographic characteristics}

Table 1 shows the sociodemographic characteristics of the sample that consisted of 2943 older adults, with the majority

Table 1: Sociodemographic characteristic of the sample by gender

\begin{tabular}{|c|c|c|c|}
\hline & \multicolumn{2}{|c|}{ Gender \% (n) } & \multirow{2}{*}{ Total \% (n) } \\
\hline & Males & Females & \\
\hline \multicolumn{4}{|l|}{ Age groups, years $(n=2919)$} \\
\hline $60-69$ & $48.0(673)$ & $40.7(618)$ & $44.2(1291)$ \\
\hline $70-79$ & $32.6(457)$ & $34.8(529)$ & $33.8(986)$ \\
\hline$\geq 80$ & $19.3(271)$ & $24.4(371)$ & $22.0(642)$ \\
\hline \multicolumn{4}{|c|}{ Parish of residence $(n=2942)$} \\
\hline St Andrew & $41.1(581)$ & $52.7(806)$ & $47.1(1387)$ \\
\hline St Catherine & $51.0(720)$ & $36.9(564)$ & $43.6(1284)$ \\
\hline St Thomas & $7.0(99)$ & 7.8 (119) & $7.4(218)$ \\
\hline Kingston & $0.8(12)$ & $2.7(41)$ & $1.8(53)$ \\
\hline \multicolumn{4}{|c|}{ Highest level of education $(n=2920)$} \\
\hline No formal schooling & $6.9(97)$ & $4.6(69)$ & $5.7(166)$ \\
\hline Primary & $70.4(988)$ & $73.5(1114)$ & $72.0(2102)$ \\
\hline Secondary & $12.9(181)$ & $11.9(181)$ & $12.4(362)$ \\
\hline Technical/vocational & $5.5(77)$ & $3.8(58)$ & $4.6(135)$ \\
\hline University & $4.3(61)$ & $6.2(94)$ & $5.3(155)$ \\
\hline \multicolumn{4}{|l|}{ Union status $(\mathrm{n}=2932)$} \\
\hline Single & $27.3(383)$ & $38.1(581)$ & $32.9(964)$ \\
\hline Married & $43.7(614)$ & $24.3(371)$ & $33.6(985)$ \\
\hline Widowed & $15.4(216)$ & $30.2(461)$ & $23.1(677)$ \\
\hline Divorced & $4.4(62)$ & $3.1(48)$ & $3.8(110)$ \\
\hline Common law & $5.4(76)$ & $1.8(27)$ & $3.5(103)$ \\
\hline Separated & $3.8(53)$ & $2.4(36)$ & $3.0(89)$ \\
\hline
\end{tabular}


$(52.0 \%, \mathrm{n}=1531)$ being female. The age of the sample ranged from 60 to 103 years, with the mean age being 72.2 (SD 8.9) years. The majority (76.9\%) of the respondents were between the ages of 60 and 79 years. Females were, on average, older $(p<0.001)$ than male respondents $(72.9$ (SD 9.0) vs 71.4 (SD 8.7) years, respectively). The majority $(77.7 \%)$ of the older adults reported that their highest level of educational attainment was primary school and below (Table $1)$.

Table 2 demonstrates that the sample was nationally representative by gender, age and rural/urban composition.

\section{Prevalence of cognitive impairment}

Scores of older Jamaican adults on the MMSE scale extended across the full range of possible scores, 0-30, with a mean of 23.1 (SD 4.8). More than one fifth $(21.2 \%, n=591)$ of older adults had mild cognitive impairment and more than one tenth $(11.0 \%, \mathrm{n}=307)$ had severe impairment. The majority $(67.7 \%, \mathrm{n}=1884)$ of older adults had no cognitive impairment.
Table 2: Percentage distribution of population, sample and subsample characteristics

\begin{tabular}{lcc}
\hline Variable & $\begin{array}{c}\text { Census 2011, population of } \\
\text { study area }\end{array}$ & Sample $(\mathbf{n}=\mathbf{2 9 4 3})$ \\
\hline Age (years) & & \\
$\quad 60-69$ & 49.9 & 44.1 \\
$70-79$ & 30.7 & 33.7 \\
$\quad \geq 80$ & 19.6 & 21.4 \\
Gender & & \\
$\quad$ Male & 47.6 & 48.0 \\
$\quad$ Female & 52.4 & 52.0 \\
Area of residence & & \\
$\quad$ Rural & 21.6 & 25.7 \\
$\quad$ Urban & 78.4 & 74.3 \\
\hline
\end{tabular}

Cognitive impairment was significantly associated with age, educational level, gender, area of residence, hospitalization in the last three years, falls in the last three months, limit activities for fear of falling, self-reported diabetes mellitus and hypertension, depression and dependence in ADL (Table 3).

Table 3: Cognitive impairment categories by variables

\begin{tabular}{|c|c|c|c|c|}
\hline \multirow{2}{*}{ Variables } & \multicolumn{3}{|c|}{ Cognitive impairment $(n=2775) \%(n)$} & \multirow{2}{*}{ Total \% (n) } \\
\hline & Severe & Mild & None & \\
\hline \multicolumn{5}{|c|}{ Age categories, years $(\mathrm{n}=2775)^{* * *}$} \\
\hline $60-69$ & $5.2(64)$ & $17.1(210)$ & $77.7(954)$ & $100(1228)$ \\
\hline $70-79$ & $9.9(93)$ & $23.8(223)$ & $66.2(620)$ & $100(936)$ \\
\hline$\geq 80$ & $24.5(150)$ & $25.7(157)$ & $49.8(304)$ & $100(611)$ \\
\hline \multicolumn{5}{|c|}{ Highest level of education $(\mathrm{n}=2762)^{* * *}$} \\
\hline Secondary and above & $4.0(25)$ & $10.2(63)$ & $85.8(530)$ & $100(618)$ \\
\hline Primary and below & $12.9(277)$ & $24.3(522)$ & $62.7(1345)$ & $100(2144)$ \\
\hline \multicolumn{5}{|l|}{ Gender $(\mathrm{n}=2782)^{* * *}$} \\
\hline Female & $12.9(185)$ & $22.6(324)$ & $64.6(927)$ & $100(1436)$ \\
\hline Male & $9.1(122)$ & $19.8(267)$ & $71.1(957)$ & $100(1346)$ \\
\hline \multicolumn{5}{|l|}{ Area of residence $(\mathrm{n}=2751)^{* *}$} \\
\hline Rural & $12.8(90)$ & $24.5(172)$ & $62.6(439)$ & $100(701)$ \\
\hline Urban & $10.1(208)$ & $20.3(417)$ & $69.5(1425)$ & $100(2050)$ \\
\hline \multicolumn{5}{|c|}{ Hospitalization in last three years $(2750)^{* * *}$} \\
\hline No & $9.8(208)$ & $21.0(447)$ & $69.2(1470)$ & $100(2125)$ \\
\hline Yes & $15.4(96)$ & $21.8(136)$ & $62.9(393)$ & $100(625)$ \\
\hline \multicolumn{5}{|c|}{ Falls in last three months $(2768)^{* * *}$} \\
\hline No & $10.4(227)$ & $20.0(437)$ & $69.6(1521)$ & $100(2185)$ \\
\hline Yes & $13.6(79)$ & $25.9(151)$ & $60.5(353)$ & $100(583)$ \\
\hline \multicolumn{5}{|c|}{ Limit activity for fear of falling $(2630)^{* * *}$} \\
\hline No & $8.6(150)$ & $18.6(324)$ & $72.8(1268)$ & $100(1742)$ \\
\hline Yes & $16.0(142)$ & $26.5 \mathrm{n}(235)$ & $57.5(511)$ & $100(888)$ \\
\hline \multicolumn{5}{|c|}{ Self-reported diabetes mellitus $(\mathrm{n}=2768)^{* *}$} \\
\hline No & $10.0(205)$ & $20.6(422)$ & $69.4(1423)$ & $100(2050)$ \\
\hline Yes & $14.1(101)$ & $23.0(165)$ & $63.0(452)$ & $100(718)$ \\
\hline \multicolumn{5}{|c|}{ Self-reported hypertension $(\mathrm{n}=2773)^{*}$} \\
\hline No & $11.5(124)$ & $18.5(199)$ & $70.0(753)$ & $100(1076)$ \\
\hline Yes & $10.8(183)$ & $22.9(389)$ & $66.3(1125)$ & $100(1697)$ \\
\hline \multicolumn{5}{|c|}{ Depression (SDS Index) $(\mathrm{n}=2355)^{* * *}$} \\
\hline No depression & $6.4(90)$ & $18.4(259)$ & $75.2(1060)$ & $100(1409)$ \\
\hline Mild depression & $15.4(88)$ & $21.0(120)$ & $63.6(363)$ & $100(571)$ \\
\hline Moderate depression & $17.4(50)$ & $31.6(91)$ & $51.0(147)$ & $100(288)$ \\
\hline Severe depression & $32.2(28)$ & $34.5(30)$ & $33.3(29)$ & $100(87)$ \\
\hline \multicolumn{5}{|l|}{ ADL (Katz Index) $(\mathrm{n}=2751)^{* * *}$} \\
\hline Independent in all & $8.8(227)$ & $20.8(533)$ & $70.4(1807)$ & $100(2567)$ \\
\hline Dependent in at least one & $41.8(77)$ & $26.1(48)$ & $32.1(59)$ & $100(184)$ \\
\hline
\end{tabular}

SDS Index: Zung Self-Rating Depression Scale; ADL: activities of daily living 
Results of the logistic regression analysis are presented in Table 4. For every one year increase in age, there was a 5\% increase in the likelihood of having cognitive impairment (OR 1.05, 95\% CI 1.04, 1.06), while older adults with a lower educational attainment were three times more likely to have cognitive impairment (OR 3.00, 95\% CI 2.23, 4.01).

Gender, area of residence, hospitalization in the last three years and having fallen in the last three months were not found to be independent predictors of cognitive impairment. Older adults who had limited their activity for fear of falling were $35 \%$ more likely to have cognitive impairment (aOR 1.35, 95\% CI 1.09, 1.67).

Older adults with self-reported diabetes mellitus were $32 \%$ more likely to have cognitive impairment (aOR 1.32 , $95 \%$ CI 1.05, 1.67). Older adults with self-reported hypertension were not found to be at greater risk for cognitive impairment (Table 4).

A one-point increase on the depression index was associated with a $2 \%$ increase in the likelihood of having cognitive impairment (aOR 1.02, 95\% CI 1.02, 1.03). Older adults dependent in at least one ADL were more than twice as likely to have cognitive impairment [aOR 2.47, 95\% CI 1.62, 3.78] (Table 4).

Table 4: Odds ratios for likelihood of having cognitive impairment

\begin{tabular}{|c|c|c|}
\hline Variable & aOR & $95 \% \mathrm{CI}^{¥}$ \\
\hline Age at last birthday & $1.05^{* * *}$ & $1.04,1.06$ \\
\hline \multicolumn{3}{|l|}{ Highest level of education } \\
\hline Secondary and above & 1.00 & - \\
\hline Primary and below & $3.00^{* * *}$ & $2.23,4.01$ \\
\hline \multicolumn{3}{|l|}{ Gender } \\
\hline Female & 1.00 & - \\
\hline Male & 0.95 & $0.77,1.17$ \\
\hline \multicolumn{3}{|l|}{ Area of residence } \\
\hline Rural & 1.00 & - \\
\hline Urban & 0.83 & $0.66,1.04$ \\
\hline \multicolumn{3}{|c|}{ Hospitalization in last three years } \\
\hline No & 1.00 & - \\
\hline Yes & 0.92 & $0.73,1.17$ \\
\hline \multicolumn{3}{|l|}{ Falls in last three months } \\
\hline No & 1.00 & - \\
\hline Yes & 1.18 & $0.93,1.51$ \\
\hline \multicolumn{3}{|l|}{ Limit activity for fear of falling } \\
\hline No & 1.00 & - \\
\hline Yes & $1.35^{* *}$ & $1.09,1.67$ \\
\hline \multicolumn{3}{|l|}{ Self- reported diabetes mellitus } \\
\hline No & 1.00 & - \\
\hline Yes & $1.32^{*}$ & $1.05,1.67$ \\
\hline \multicolumn{3}{|l|}{ Self- reported hypertension } \\
\hline No & 1.00 & - \\
\hline Yes & 0.84 & $0.67,1.05$ \\
\hline Depression (SDS Index) & $1.02^{* * *}$ & $1.02,1.03$ \\
\hline \multicolumn{3}{|l|}{ ADL (Katz Index) } \\
\hline Independent in all & 1.00 & - \\
\hline Dependent in at least one & $2.47^{* * *}$ & $1.62,3.78$ \\
\hline
\end{tabular}

${ }^{*} p<0.05,{ }^{* *} p<0.01,{ }^{* * *} p<0.001$

SDS Index: Zung Self-Rating Depression Scale; ADL: activities of daily living

\section{DISCUSSION}

Despite compensating for the age and lower educational attainment of the sample by adjusting the cut-point for the MMSE, the prevalence of cognitive impairment $(32.2 \%)$ among community-dwelling older adults in Jamaica is much higher than previous studies in Jamaica which used a higher cut-point of 23/24 for the MMSE (30). Other studies using the cut-point of $23 / 24$ documented lower cognitive impairment prevalence of $17.0 \%$ in Korea (36), 18.3\% in the United Kingdom (37) and 20.4\% in Poland (38). In a Brazilian population of similar age and educational attainment as Jamaica, using a cut-point of 22/23, the prevalence of cognitive impairment was $34.0 \%$ (39).

Most of the cases of severe cognitive impairment either have dementia or are at high risk of developing dementia, while many older adults with mild cognitive impairment may never progress to dementia (40). The reported prevalence must be viewed in that context. Given rapid population ageing, the prevalence of cognitive impairment and dementia is expected to increase; so too will the associated need for specialized health services, caregivers, community support and long-term care facilities.

There is a window of opportunity (demographic dividend) for developing countries like Jamaica, where the large numbers of persons in the working-age group can induce economic growth (41). This demographic dividend, managed well, can allow for development of appropriate and evidence-based services, policies and programmes to improve patient outcomes and reduce potential costs $(12,42)$.

Our findings of variables predicting an association with cognitive impairment build upon previous work among older adults (13-29). In this study, self-reported hypertension was not a significant predictor of cognitive impairment. The literature reports conflicting results regarding the influence of hypertension and gender on cognitive impairment $(29,43-$ 45). Gender, though significant in bivariate analysis, was not found to be an independent predictor in this study when the other variables were introduced in the regression model. Interactions between age, gender, education and the presence of diabetes, when controlled for, may explain this finding. Similarly, interactions between area of residence, education, hospitalizations, falls and gender may help explain associations of cognitive impairment in bivariate analysis but lack of significance in regression models. Hospitalization is influenced by access, cultural norms and perceptions of the quality of care. In the Jamaican context, these would tend to reduce hospitalization rates.

The prevalence of cognitive impairment may have been under-estimated as older adults with severe cognitive impairment are arguably less likely to participate in a community-based study. Moreover, institutionalized older adults were not included. These seminal results in Jamaica argue for further research to determine a) the most appropriate cutpoint for MMSE in Jamaican elders, b) the prevalence of 
dementia among MMSE screen-positives, c) dementia aetiology and d) the most appropriate interventions to reduce the risk for cognitive impairment and dementia and reduce associated morbidity and mortality.

\section{ACKNOWLEDGEMENTS}

The authors thank the National Health Fund for their financial support of this study.

\section{REFERENCES}

1. Prince M, Bryce R, Albanese E, Wimo A, Ribeiro W, Ferri CP. The global prevalence of dementia: a systematic review and metaanalysis. Alzheimers Dement 2013; 9: 63-75.

2. Alzheimer's Disease International. World Alzheimer report 2009. Chicago: Alzheimer's Disease International; 2009 [cited 2014 Jun 01]. Available from: http://www.alz.co.uk/research/files/WorldAlzheimer Report.pdf

3. Mavrodaris A, Powell J, Thorogood M. Prevalences of dementia and cognitive impairment among older people in sub-Saharan Africa: a systematic review. Bull World Health Organ 2013; 91: 773-83.

4. Alzheimer's Disease International. Policy brief for heads of government. The global impact of dementia 2013-2050. Chicago: Alzheimer's Disease International; 2013 [cited 2014 Jun 01]. Available from: http://www.alz.co.uk/research/GlobalImpactDementia2013.pdf

5. Folstein MF, Folstein SE, McHugh PR. "Mini-mental state". A practical method for grading the cognitive state of patients for the clinician. J Psychiatr Res 1975; 12: 189-98.

6. Folstein MF, Robins LN, Helzer JE. The mini-mental state examination. Arch Gen Psychiatry 1983; 40: 812.

7. Chow TW, Hynan LS, Liptond AM. MMSE scores decline at a greater rate in frontotemporal degeneration than in AD. Dement Geriatr Cogn Disord 2006; 22: 194-9.

8. Gagnon M, Letenneur L, Dartigues JF, Commenges D, Orgogozo JM, Barberger-Gateau P et al. Validity of the mini-mental state examination as a screening instrument for cognitive impairment and dementia in French elderly community residents. Neuroepidemiology 1990; 9: $143-50$.

9. Grut M, Fratiglioni L, Viitanen M, Winblad B. Accuracy of the minimental status examination as a screening test for dementia in a Swedish elderly population. Acta Neurol Scand 1993; 87: 312-7.

10. Jeong SK, Cho KH, Kim JM. The usefulness of the Korean version of modified Mini-Mental State Examination (K-mMMSE) for dementia screening in community dwelling elderly people. BMC Public Health 2004; 4: 31 .

11. Kochhann R, Varela JS, Lisboa CSM, Chaves MLF. The mini mental state examination review of cutoff points adjusted for schooling in a large southern Brazilian sample. Dement Neuropsychol 2010; 4: 35-41.

12. Lin JS, O'Connor E, Rossom RC, Perdue LA, Eckstrom E. Screening for cognitive impairment in older adults: a systematic review for the U.S. preventive services task force. Ann Intern Med 2013; 159: 601-12.

13. de Brito-Marques PR, Cabral-Filho JE. Influence of age and schooling on the performance in a modified mini-mental state examination version: a study in Brazil northeast. Arq Neuro-psiquiatr 2005; 63: 583-7.

14. Laks J, Baptista EM, Contino AL, de Paula EO, Engelhardt E. MiniMental State Examination norms in a community dwelling sample of elderly with low schooling in Brazil. Cad Saude Publica 2007; 23: 315-9.

15. Kochhann R, Cerveira MO, Godinho C, Camozzato A, Chaves MLF Evaluation of Mini-Mental State Examination scores according to different age and education strata, and sex, in a large Brazilian healthy sample. Dement Neuropsychol 2009; 3: 88-93.

16. Nunes B, Silva RD, Cruz VT, Roriz JM, Pais J, Silva MC. Prevalence and pattern of cognitive impairment in rural and urban populations from northern Portugal. BMC Neurology 2010; 10: 42.
17. Davydow DS, Zivin K, Katon WJ, Pontone GM, Chwastiak L, Langa KM et al. Neuropsychiatric disorders and potentially preventable hospitalizations in a prospective cohort study of older Americans. J Gen Intern Med 2014; 29: 1362-71. DOI: 10.1007/s11606-014-2916-8.

18. Phelan EA, Borson S, Grothaus L, Balch S, Larson EB. Association of incident dementia with hospitalizations. JAMA 2012; 307: 165-72.

19. Gleason CE, Gangnon RE, Fischer BL, Mahoney JE. Increased risk for falling associated with subtle cognitive impairment: secondary analysis of a randomized clinical trial. Dement Geriatr Cogn Disord 2009; 27: 557-63.

20. Herman T, Mirelman A, Giladi N, Schweiger A, Hausdorff JM. Executive control deficits as a prodrome to falls in healthy older adults: a prospective study linking thinking, walking, and falling. J Gerontol A Biol Sci Med Sci 2010; 65: 1086-92.

21. Uemura K, Shimada H, Makizako H, Doi T, Tsutsumimoto K, Yoshida $\mathrm{D}$ et al. Effects of mild and global cognitive impairment on the prevalence of fear of falling in community-dwelling older adults. Maturitas 2014; 78: 62-6.

22. Borges SD, Radanovic M, Forlenza OV. Fear of falling and falls in older adults with mild cognitive impairment and Alzheimer's disease. Neuropsychol Dev Cogn B Aging Neuropsychol Cogn 2014; 3: 1-10.

23. Ruis C, Biessels GJ, Gorter KJ, van den Donk M, Kappelle LJ, Rutten GEHM. Cognition in the early stage of type 2 diabetes. Diabetes Care 2009; 32: 1261-5.

24. Stewart R, Liolitsa D. Type 2 diabetes mellitus, cognitive impairment and dementia. Diabet Med 1999; 16: 93-112.

25. Sarró-Maluquer M, Ferrer-Feliu A, Rando-Matos Y, Formiga F, RojasFarreras S; en representación del Grupo de Estudio Octabaix. Depression in the elderly: prevalence and associated factors. Semergen 2013; 39: 354-60.

26. Perneczky R, Pohl C, Sorg C, Hartmann J, Komossa K, Alexopoulos P et al. Complex activities of daily living in mild cognitive impairment: conceptual and diagnostic issues. Age Ageing 2006; 35: 240-5.

27. Katz MJ, Lipton RB, Hall CB, Zimmerman ME, Sanders AE, Verghese $\mathrm{J}$ et al. Age-specific and sex-specific prevalence and incidence of mild cognitive impairment, dementia, and Alzheimer dementia in blacks and whites: a report from the Einstein Aging Study. Alzheimer Dis Assoc Disord 2012; 26: 335-43.

28. Zhang Z. Gender differentials in cognitive impairment and decline of the oldest old in China. J Gerontol B Psychol Sci Soc Sci 2006; 61: S107-15.

29. Sharifi F, Hedayat M, Fakhrzadeh H, Mahmoudi MJ, Ghaderpanahi M, Mirarefin $\mathrm{M}$ et al. Hypertension and cognitive impairment: Kahrizak Elderly Study. Int J Gerontol 2011; 5: 212-16.

30. Eldemire D. An epidemiological study of the Jamaican elderly [PhD dissertation]. Kingston, Jamaica: The University of the West Indies; 1993.

31. Mitchell-Fearon K, Waldron N, James K, Laws H, Holder-Nevins D, Eldemire-Shearer D. Hypertension and diabetes prevalence in older persons in Jamaica. West Indian Med J 2014; 63: 420-7.

32. Rosselli M, Tappen R, Williams C, Salvatierra J. The relation of education and gender on the attention items of the Mini-Mental State Examination in Spanish speaking Hispanic elders. Arch Clin Neuropsychol 2006; 21: 677-86.

33. Zung WW. A self-rating depression scale. Arch Gen Psychiatry 1965; 12: $63-70$.

34. Katz S, Ford AB, Moskowitz RW, Jackson BA, Jaffe MW. Studies of illness in the aged. The index of ADL: a standardized measure of biological and psychosocial function. JAMA 1963; 185: 914-9.

35. Katz S, Downs TD, Cash HR, Grotz RC. Progress in development of the index of ADL. Gerontologist 1970; 10: 20-30.

36. Park B, Park J, Jun JK. Cognitive impairment, depression, comorbidity of the two and associated factors among the early sixties in a rural Korean community. PLoS One 2013; 8: e79460. DOI: 10.1371/ journal.pone.0079460.

37. Rait G, Fletcher A, Smeeth L, Brayne C, Stirling S, Nunes M et al. Prevalence of cognitive impairment: results from the MRC trial of 
assessment and management of older people in the community. Age Ageing 2005; 34: 242-8.

38. Klich-Rączka A, Piotrowicz K, Mossakowska M, Skalska A, Wizner B, Broczek $\mathrm{K}$ et al. The assessment of cognitive impairment suspected of dementia in Polish elderly people: results of the population-based PolSenior Study. Exp Gerontol 2014; 57: 233-42. DOI: 10.1016/j. exger.2014.06.003.

39. Holz AW, Nunes BP, Thumé E, Lange C, Facchini LA. Prevalence of cognitive impairment and associated factors among the elderly in Bagé, Rio Grande do Sul, Brazil. Rev Bras Epidemiol 2013; 16: 880-8.

40. Boustani M, Peterson B, Hanson L, Harris R, Lohr KN. Screening for dementia in primary care: a summary of the evidence for the US Preventive Services Task Force. Ann Intern Med 2003; 138: 927-37.

41. United Nations, Department of Economic and Social Affairs, Population Division. World population ageing 2013. New York: United Nations; 2013 [cited 2014 Jul 15]. Available from: http://www.un. org/en/development/desa/population/publications/pdf/ageing/WorldPop ulationAgeing2013.pdf

42. Eldemire-Shearer D. Ageing: the response yesterday, today and tomorrow. West Indian Med J 2008; 57: 577- 88 .

43. Morris MC, Scherr PA, Hebert LE, Bennett DA, Wilson RS, Glynn RJ et al. The cross-sectional association between blood pressure and Alzheimer's disease in a biracial community population of older persons. J Gerontol A Biol Sci Med Sci 2000; 55: M130-6.
44. Reitz E, Tang M, Manly J, Mayeux R, Luchsinger JA. Hypertension and the risk of mild cognitive impairment. Arch Neurol 2007; 64: 1734-40.

45. Zhuang J, Wang G, Cheng Q, Wang L, Fang R, Liu L et al. Cognitive impairment and the associated risk factors among the elderly in the Shanghai urban area: a pilot study from China. Transl Neurodegener 2012; 1: 22. DOI: 10.1186/2047-9158-1-22.

Received 27 Aug 2014

Accepted 08 Sep 2014

Published 28 May 2015

Online: http://www.mona.uwi.edu/wimjopen/article/1640

(C) Waldron et al 2015

This is an open access article made freely available under Creative Commons Attribution 4.0 International (CC BY 4.0). Users are free to share, copy and adapt this work as long as the copyright holder (author) is appropriately and correctly credited. See http://creativecommons.org/ licences/by/4.0/deed.en_us for more information. 